\author{
Military Technical College \\ Kobry El-Kobbah, \\ Cairo, Egypt.
}

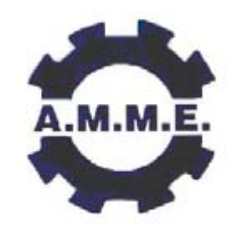

\title{
UTILIZATION OF NANOCRYSTALLINE DIAMOND POWDER IN RUBBER COMPOUNDS AS A NOVEL REINFORCING MATERIAL
}

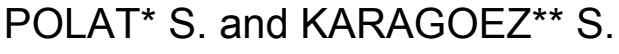

\begin{abstract}
Nano scaled materials have improved mechanical properties compared to the conventional ones due to their extremely large surface areas. Nano silicon carbide, nano zinc oxide, nano clays, nano starch and nano alumina can be named among many others. The nanocrystalline diamond powder used in this study as rubber reinforcing material has been synthesized by explosive detonation, a method that gained importance since the mid 1980s. Free carbon atoms are released when an explosive deficient in oxygen, usually a TNT/RDX (trinitrotoluene/hexogene) mixture, is detonated in a preservative material. Nano-sized diamond crystallites are formed by coagulation and rearrangement of these carbon atoms under the high temperature and high pressure condition produced by the detonation reaction. Diamond powder synthesized by explosive detonation has a particle size in the range $1-15 \mathrm{~nm}$. It is well known that particle size of a filler must be lower than $100 \mathrm{~nm}$ in order to have a reinforcing effect in rubber compounds. Thus, nanocrystalline diamond powder has a great potential, as a rubber reinforcing material, provided that it is well dispersed and can be attached to the polymer molecules. In the present study diamond powder is added to a rubber formulation used on tank pallets at varying phr (parts per hundred parts of rubber, by weight) values. The change in physical and mechanical properties of the compound has been investigated and considerable improvement is observed in abrasion resistance even at low phr levels.
\end{abstract}

\section{KEY WORDS}

Nanotechnology, Nanocomposite, Nanocrystalline diamond, Ultrafine dispersed diamond (UDD), Synthesis by explosive detonation, Rubber compound, Reinforcing material, Abrasion resistance

\footnotetext{
* Assist. Prof . Dr, Dpt. of Metallurgical and Materials Engineering, Kocaeli University, Turkey

** Prof. Dr.,Dpt. of Metallurgical and Materials Engineering, Kocaeli University, Turkey
} 


\section{INTRODUCTION}

Nanoparticles are ultra fine dispersive particles with diameters below $100 \mathrm{~nm}$ having a very high surface-to-volume ratio. Nano-sized reinforcing particles are added to rubber compounds in dry powder form and improve their physical and mechanical properties drastically, provided that they are well dispersed within the matrix and can be attached to the polymer molecules. A filler has reinforcing effect, namely it improves the modulus and failure properties like tensile strength, tear resistance and abrasion resistance of the final vulcanizate, if its particle size is less than $100 \mathrm{~nm}$. Reinforcement is very much dependent on the particle size of the filler because by decreasing particle size surface area per gram of filler increases. Thus, the effect of smaller particles actually reflects their greater extent of interface between polymer and filler. Besides carbon black, which is the most important filler used in rubber, various nano-sized powders with particle sizes less than $20 \mathrm{~nm}$ have been introduced in recent years. Nano clays have a great potential in that respect due to their considerably lower cost and are widely used in many thermoplastics, resins and elastomers. Nano silicon carbide, patented by Cabot Corporation (PureNano ${ }^{\mathrm{TM}} \mathrm{SiC}$ ), is claimed to improve the abrasion resistance of rubber compounds up to \% 50 [1]. Goodyear Tire \& Rubber Company announced a similar achievement by using nano-sized $\mathrm{ZnO}$ particles in rubber [2]. Nanocrystalline diamond powder used in this study is synthesized by explosive detonation. Its particle size is in the range 1-15 $\mathrm{nm}$ and thus it has a great potential as a rubber reinforcing filler. Promising results were obtained during the preliminary studies [3].

\section{EXPERIMENTAL STUDY}

\section{Material}

Synthesis of nano-scaled crystalline diamond powder by explosive detonation, has gained importance since the mid 1980s. The initial step of this process is detonation of an explosive deficient in oxygen, usually a TNT/RDX (trinitrotoluene/hexogene) mixture, in a preservative material. As a result free carbon atoms are released and nano-sized diamond crystallites are formed by coagulation and rearrangement of these carbon atoms under the high temperature and high pressure condition produced by the detonation reaction. Detonation soot obtained after cooling contains graphite and amorphous carbon besides the nanodiamonds (ultrafine dispesed diamonds, UDDs). The final step of the process is purification of the carbon blend, where the UDDs are separated from the other carbon products and non-carbon impurities coming from the wall material of the blast chamber. The UDD yield can be increased by optimization of the process parameters. Diamond crystals synthesized by this method are rather small $(1-15 \mathrm{~nm})$ and are incorporated in various aggregated particles. Their structural, electronic, optical and magnetic properties are investigated by means of XRD, SAXS, HRTEM, FTIR, EPR, NMR [4-19].

The model structure of detonation-produced carbon has a diamond core which is coated by an onion-like carbon shell, on which graphite inclusions and various impurities are distributed. [7]. By the help of this outer shell nanocrystalline diamond can be attached to the rubber molecules.

Nanocrystalline diamond powder used in the this study has been supplied by Advanced Technology Materials Research and Development Co. (Gebze, TURKEY), which is the 
only producer of this material in Turkey. The trial production of this material was started in 2004 by this company through the purchase of patent rights of US Patent $5,353,708$ [20]. The particle size is reported to be within the range of $1-10 \mathrm{~nm}$ and the average size around $3 \mathrm{~nm}$.

\section{Preparation of Rubber Compounds}

The rubber compounds used in the study are prepared and tested at the rubber workshop of the $1^{\text {st }}$ Maintenance Center of the Turkish Land Forces Command at Arifiye-Adapazarı. The compounds having 0.0-5.0 phr nanocrystalline diamond powder are prepared by a 2 roll laboratory mill, as $1 \mathrm{~kg}$ batches. In rubber technology, all the ingredients used in a compound are given in amounts based on a total of 100 parts of the rubber or combinations of rubbers. This notation is given as phr (parts per hundred parts of rubber, by weight). The details of the compound recipe will not be given here due to the secrecy agreement. Nevertheless it contains natural rubber and two other synthetic rubbers. The main filler in the recipe is a high reinforcing grade carbon black. Rheometer, tensometer, durometer, abrasion resistance tester are used to determine the vulcanization parameters, physical and mechanical properties of the compounds. Results are evaluated with respect to the control compound which has no diamond reinforcement (0.0 phr loading).

\section{RESULTS AND DISCUSSION}

The vulcanization parameters of the compounds are determined by an oscillating disc type rheometer (Monsanto $100 \mathrm{~S}$ ) at $175^{\circ} \mathrm{C}$ according to ASTM D2084 and results are listed in Table 1 . The time to $90 \%$ cure $\left(t_{90}\right)$, minimum torque $\left(\mathrm{M}_{\mathrm{L}}\right)$ and maximum torque $\left(\mathrm{M}_{\mathrm{H}}\right)$ are given for each compound.

The torque values $\left(\mathrm{M}_{\mathrm{L}}, \mathrm{M}_{\mathrm{H}}\right)$ increase by increasing diamond loading, as expected. This is an indication of the reinforcing effect of nanocrystalline diamond powder. The time to $90 \%$ cure decreases as loading increases and this can be attributed to the remaining metallic impurities within the diamond powder.

Stress-strain tests of compounds, vulcanized at $155^{\circ} \mathrm{C}$ for 30 minutes, are carried out by a tensometer (Zwick Z010) according to DIN 53504. Tensile strength at break, elongation at break and modulus at $300 \%$ elongation $\left(\mathrm{M}_{300}\right)$ are determined. Hardness values of the same compounds are obtained by a Zwick Durometer according to DIN 53505. Results are shown in Table 2.

According to the data in Table 2, when nanocrystalline diamond powder is added to the compounds elongation at break is lowered as expected due to the increasing hardness. At highest loading (5.0 phr) appreciable decrease in tensile strength at break is also observed. This result is not surprising since after a critical loading all reinforcing powders have negative effect on mechanical properties of the compounds. On the other hand, modulus at $300 \%$ elongation and hardness increase by increasing diamond content, indicating the reinforcing effect of this material.

ZWICK Abrasion Tester is used to determine the abrasion resistance of the compounds according to DIN 53516 and improvement up to $37 \%$ with respect to the control compound is observed. Results are shown in Table 3 and Fig.1. Optimum diamond 
loading appears to be between 1.0 - $2.0 \mathrm{phr}$ since there is no gain in abrasion resistance at higher values and also sacrifice in mechanical properties is lower.

\section{CONCLUSIONS}

Current work has revealed that nano-scaled crystalline diamond powder from explosive detonation, can be a powerful reinforcing material for rubber compounds. The trial compounds loaded with diamond powder at varying values from 0.5 to $5.0 \mathrm{phr}$ are prepared and tested. Results are compared with the control compound which does not contain this material ( 0 phr). Hardness and modulus at \%300 elongation increase by increasing the diamond loading. In the same manner, rheometer data shows that minimum and maximum torque values increase as well. These results all indicate the reinforcing effect of the new material. A sacrifice in mechanical properties like tensile strength and elongation at break is observed which denotes that the loading needs to be kept at an optimum level. The abrasion test reveals that maximum improvement in abrasion resistance is attained at 2.0 phr loading. Thus, it can be concluded that for the given compound recepie, diamond powder loading should be kept at about 1.0 - $2.0 \mathrm{phr}$ level in order to get highest improvement in abrasion resistance without sacrificing much from the mechanical properties.

The next project will be to follow the performance of tank pallets produced by the trial compounds, in the field. In order to be able to use this powder in serial production without problems, its properties, and rubber mixing parameters must be well determined.

\section{ACKNOWLEDGEMENT}

This project has been supported by the State Planning Organization of Turkey, DPT (Project No. 2003-K120790) and Unit of Scientific Research Projects at Kocaeli University (Project No. 2003-59). Advanced Technology Materials Research and Development Co. has kindly supplied the nano-scaled crystalline diamond powder used in the study and $1^{\text {st }}$ Maintenance Center of the Turkish Land Forces Command at Arifiye-Adapazarı allowed us to use their rubber workshop for preparation and testing of the rubber compounds. We gratefully acknowledge all of these institutions.

\section{REFERENCES}

[1] US Patent 6,469,089 "Elastomeric compounds with improved wet skid resistance and methods to improve wet skid resistance", Assignee: Cabot Co., October, (1999).

[2] US Patent Application No. 20050027054 "Rubber composition containing nanoscaled zinc oxide particles”, Goodyear Tire \& Rubber Co., February, (2005).

[3] Polat S., Karagoz S., "Nano-kristalin Elmas Tozunun Ozellikleri ve Elastomer Teknolojisinde Kullanımı", $4^{\text {th }}$ International Powder Metallurgy Conference, Sakarya University, Adapazarı, Turkey, May (2005).

[4] Thiel M.van, Ree F.H., Journal of Applied Physics, 62(5), 1761, (1987). 
[5] V.L.Kuznetsov, M.N.Aleksandrov, I.V.Zagoruiko, A.L.Chuvilin, E.M.Moroz, V.N.Kolomiichuk, V.A.Likholobov, P.M.Brylyakov and G.V.Sakovitch, Carbon, 29(4-5), 665, (1991).

[6] V.L.Kuznetsov, A.L.Chuvilin, E.M.Moroz, V.N.Kolomiichuk, Sh.K.Shaikhutdinov, Yu.V.Butenko and I.Yu.Mal'kov, Carbon, 32(5), 873, (1994).

[7] A.E.Aleksenskii, M.V.Baidakova, A.Ya.Vul and V.I.Siklitskii, Physics of the Solid State, 41(4), 668, (1999).

[8] K.lakoubovskii, G.J.Adriaenssens, K.Meykens, M.Nesladek, A.Ya.Vul and V.Y.Osipov, Diamond and Related Materials, 8, 1476, (1999).

[9] J.P.Donnet, E.Fousson, L.Delmotte, M.Samirant, C.Baras, T.K.Wang and A.Eckhardt, C.R. Acad. Sci. Paris, Serie Ilc, Chimie / Chemistry, 3, 831, (2000).

[10] K.lakoubovskii, M.V.Baidakova, B.H.Wouters, A.Stesmans, G.J.Adriaenssens, A.Ya.Vul and P.J.Grobet, Diamond and Related Materials, 9, 861, (2000).

[11] P.W.Chen, Y.S.Ding, Q.Chen, F.L.Huang and S.R.Yun, Diamond and Related Materials, 9, 1722, (2000).

[12] Q.Chen and S.Yun, Materials Research Bulletin, 35, 1915, (2000).

[13] Yu.V.Butenko, V.L.Kuznetsov, A.L.Chuvilin, V.N.Kolomiichuk, S.V.Stankus, R.A.Khairulin and B.Segall, Journal of Applied Physics, 88(7), 4380, (2000).

[14] G.A.Chiganova, Inorganic Materials, 37(10), 1006, (2001).

[15] E.Mironov, A.Koretz and E.Petrov, Diamond and Related Materials, 11,872, (2002).

[16] A.I.Shames, A.M.Panich, W.Kempinski, A.E.Alexenskii, M.V.Baidakova, A.T.Dideikin, V.Yu.Osipov, V.I.Siklitski, E.Osawa, M.Ozawa and A.Ya.Vul, Journal of Physics and Chemistry of Solids, 63,1993, (2002).

[17] E.Mironov, E.Petrov and A.Koretz, Diamond and Related Materials, 12, 1472, (2003).

[18] L.A.Bursill, A.L.Fullerton and L.N.Bourgeois, International Journal of Modern Physics B, 15(31), 4087, (2001).

[19] J.L.Peng, S.Bulcock, P.I.Belobrov and L.A.Bursill, International Journal of Modern Physics B, 15(31), 4071, (2001).

[20] US Patent 5,353,708 "Method for production of ultrdispersed diamond", Inventors: S.Y.Stavrev, S.B.Lazarov, K.L.Stoev, L.G.Markov and V.I.Ivanov, October (1994) 


\section{TABLES:}

Table 1. Vulcanization parameters

\begin{tabular}{|c|c|c|c|}
\hline \multirow{2}{*}{$\begin{array}{c}\text { Diamond } \\
\text { (phr) }\end{array}$} & \multicolumn{3}{|c|}{ Cure Test (Rheometer, $175^{\circ} \mathrm{C}$ ) } \\
\cline { 2 - 4 } & $\mathrm{t}_{90}(\mathrm{~min})$ & $\mathrm{M}_{\mathrm{L}}$ (inch-lb) & $\mathrm{M}_{\mathrm{H}}$ (inch-lb) \\
\hline 0.0 & 6.8 & 7.3 & 40.7 \\
0.5 & 6.2 & 10.6 & 44.9 \\
1.0 & 6.1 & 10.2 & 43.9 \\
2.0 & 5.9 & 11.6 & 44.0 \\
3.0 & 5.3 & 11.7 & 45.2 \\
4.0 & 6.0 & 13.0 & 49.0 \\
5.0 & 5.6 & 12.3 & 45.7 \\
\hline
\end{tabular}

Table 2. Physical and mechanical properties.

\begin{tabular}{|c|c|c|c|c|}
\hline $\begin{array}{c}\text { Diamond } \\
\text { (phr) }\end{array}$ & $\begin{array}{c}\text { Tensile } \\
\text { Strength at } \\
\text { Break } \\
\left(\mathrm{N} / \mathrm{mm}^{2}\right)\end{array}$ & $\begin{array}{c}\text { Elongation at } \\
\text { Break } \\
\left(\% / \mathrm{mm}^{2}\right)\end{array}$ & $\begin{array}{c}\text { Hardness } \\
\text { (Shore } \mathrm{A})\end{array}$ \\
\hline 0.0 & 12.46 & 18.89 & 426.77 & 70 \\
0.5 & 14.52 & 17.26 & 347.24 & 73 \\
1.0 & 13.81 & 17.80 & 378.05 & 71 \\
2.0 & 15.54 & 19.26 & 372.85 & 74 \\
3.0 & 14.53 & 16.44 & 339.80 & 75 \\
4.0 & 16.16 & 18.83 & 356.16 & 76 \\
5.0 & 14.07 & 15.39 & 332.72 & 75 \\
\hline
\end{tabular}

Table 3. Abrasion test results.

\begin{tabular}{|c|c|c|c|}
\hline $\begin{array}{c}\text { Diamond } \\
\text { (phr) }\end{array}$ & $\begin{array}{c}\text { Volume Loss } \\
\left(\mathrm{cm}^{3}\right)\end{array}$ & $\begin{array}{c}\text { Abrasion } \\
(\%)\end{array}$ & $\begin{array}{c}\text { Abrasion } \\
\text { Index }\end{array}$ \\
\hline 0,0 & 0,220 & 10,31 & 100 \\
0,5 & 0,150 & 7,44 & 128 \\
1,0 & 0,123 & 6,73 & 135 \\
2,0 & 0,131 & 6,48 & 137 \\
3,0 & 0,143 & 7,05 & 132 \\
4,0 & 0,143 & 7,16 & 131 \\
5,0 & 0,148 & 7,26 & 130 \\
\hline
\end{tabular}


FIGURE:

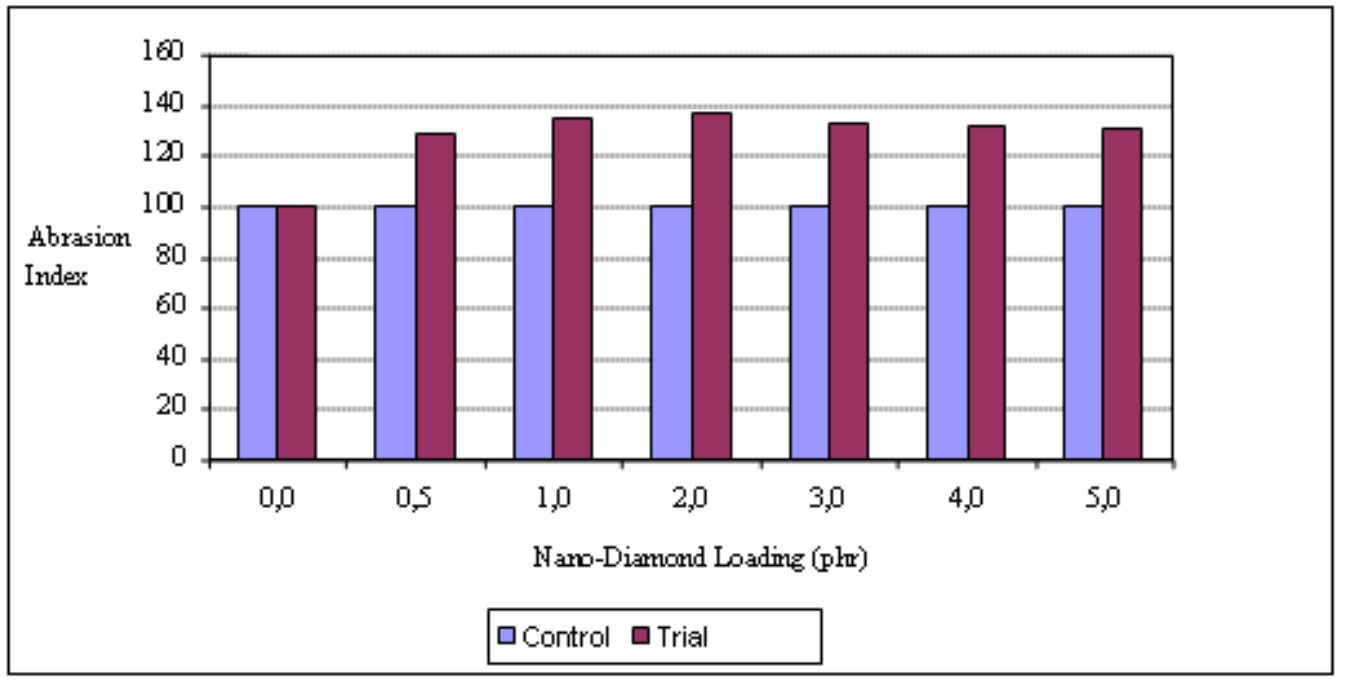

Fig.1. Change in Abrasion Index with respect to diamond. 